\title{
ARTIGOS
}

\section{DESIGN DE INTERIORES COMO FERRAMENTA PARA SUSTENTABILIDADE}

\author{
INTERIOR DESIGN AS A TOOL FOR SUSTAINABILITY
}

\author{
ANA LÚCIA KEIKO NISHIDA, Esp. | UNOPAR \\ DAMARES LUIZA SILVEIRA DE CARVALHO, M.SC. | UNOPAR
}

\begin{abstract}
RESUMO
Este artigo é resultado do projeto de extensão permanente, intitulado Utilização de Materiais de Descarte na Fabricação de Pisos, Revestimentos e Mobiliários (Reveste), da Universidade Norte do Paraná (UNOPAR) do curso de Tecnologia em Design de Interiores. Com o objetivo de evidenciar as formas de reutilização dos materiais em fase de descarte, este artigo mostra o estudo realizado para o desenvolvimento e execução de móveis e artefatos decorativos a partir de princípios sustentáveis. Os mobiliários desenvolvidos foram feitos para a feira anual expo londrina 2017 e para o centro de educação Infantil Governador Jose Richa, que ocorreu em março para a exposição e em seguida no mês de dezembro ao final do ano letivo. Onde a comunidade pôde conhecer e receber as informações do processo de estudo, de desenvolvimento e execução dos móveis. Os materiais utilizados para o estudo foram pneus, caixas de feira, pallets, caixas de para-brisas automotivos e sementes impróprias para consumo.
\end{abstract}

PALAVRAS CHAVE: Sustentabilidade; Reutilização; Design de interiores

\begin{abstract}
This article is the result of the permanent extension project titled Use of Discard Materials in the Manufacture of Floors, Coatings and Furnishings (Reveste) of the University of North of Parana (UNOPAR) of the course of Technology in Interior Design. With the purpose of evidencing the ways of reuse of the materials in phase of discard, this article shows the study realized for the development and execution of furniture and decorative artifacts from sustainable principles. The furniture developed was made for the annual expo london 2017 fair and for the Governor Jose Richa Infantile education center, which took place in March for the exhibition and then in the month of December at the end of the school year. Where the community was able to know and receive the information of the process of study, development and execution of furniture. The materials used for the study were tires, fair boxes, pallets, automotive windshield boxes and seeds unfit for consumption.
\end{abstract}

KEY WORDS: Sustainability; Reuse; Interior design 


\section{INTRODUÇÃO}

O conceito ecodesign surgiu no início dos anos 1990, quando as indústrias eletrônicas dos Estados Unidos desenvolveram produtos menos agressivos ao meio ambiente, e a partir deste momento o interesse por este tema cresceu, segundo Fiksel (1996, apud Junior, 2015).

Associação Empresarial de Portugal (AEP) define o ecodesign como a integração das áreas de Design, Arquitetura e Engenharia, que reflete uma tendência mundial, e tem como objetivo desenvolver produtos, sistemas e serviços que tornem mínimo o impacto ambiental. A necessidade de planos que visem a sustentabilidade do setor, justifica a busca por novos projetos que especifiquem um menor número de matéria prima virgem, utilizando assim no seu processo materiais alternativos.

Para Lima (2010) o consumo desenfreado dos recursos naturais ocasionou inúmeros impactos ao meio ambiente, levando a questionar a viabilidade de uma existência digna para as futuras gerações da sociedade.

O objetivo deste artigo é apresentar formas de reutilização de materiais, em fase de descarte, no processo de elaboração e produção de mobiliários e objetos de decoração para aplicação no Design de Interiores. A decoração de interiores, por estar relacionada na escolha de materiais ou mobiliários, cores, tipos de iluminação, pode propor alternativas que associe o menor impacto ambiental sem renunciar a tecnologia, para Coutinho (2013).

O resultado desse trabalho foi exposto na Expo Londrina nos estandes da EMATER (Empresa de Assistência Técnica e Extensão Rural) e Platôs de descanso da Via Rural, durante o evento Expo Londrina edição 2017. E outros mobiliários desenvolvidos foram entregues ao Centro de Educação Infantil Governador Jose Richa, ao final do ano letivo de 2017 Os objetos desenvolvidos neste trabalho foram: pufes, mesas de centro, sofás e placas decorativas, onde os visitantes puderam receber informações de todo o processo de projeto e fabricação do material desenvolvido.

A AEP (2013) afirma que o design ecológico exerce um papel educativo, sensibilizando o consumidor e assim o fazendo refletir sobre os impactos ambientais negativos causados por determinados processos produtivos e sobre as maneiras de minimizar esses impactos, por meio do consumo de produtos, sistemas e serviços ecologicamente corretos.

\section{PRINCÍPIOS SUSTENTÁVEIS NO DESIGN DE INTERIORES}

A sustentabilidade tem ganhado cada vez mais espaço e atenção em nossa sociedade. No Brasil a quantidade de resíduos sólidos produzido é semelhante a quantidade gerada em países desenvolvidos, porém o padrão de descarte equivale ao de países pobres, com envio para lixões a céu aberto e pouca reciclagem, Girardi (2016). O impacto ambiental causado pela produção e descarte é um dos principais do planeta segundo Cortês (2011) e Junior (2013).

Na construção civil segundo Rezende (2017) a produção de resíduos é um fator de grande preocupação, pois uma vez que não haja destinação adequada desse material no meio ambiente e interferindo na paisagem urbana e no patrimônio natural que ainda existe.

Para o campo do design de interiores também está sujeito a geração de resíduos, seja eles resultados de reformas, assim como no desenvolvimento de artefatos, mobiliários, material de acabamentos. No design de interiores a sustentabilidade é aplicada na concepção e especificação de móveis e artefatos, na aplicação de revestimentos, tintas ecológicas, bem como no planejamento de sistemas de captação de água pluvial, iluminação natural, ventilação entre outros. Neste contexto o designer de interiores deve buscar soluções frente ao alto consumo de produtos e geração de resíduos.

Para Menegucci (2015) a pratica da sustentabilidade é primordial para reverter o quadro da exploração excessiva dos recursos naturais, e que pode resultar em meIhores condições de vida para as pessoas. Por meio da reutilização de materiais descartados, é possível, evitar o uso de recursos naturais e diminuindo a extração de matéria prima bruta e como consequência a redução da degradação do ambiente.

Em 2009 o Instituto 5 Elementos desenvolveu o manual "Consumo sustentável e manual de atividades", a qual são descritos o princípio dos 5R (Repensar, Reduzir, Recusar, Reutilizar e Reciclar) uma ferramenta importante para o consumo consciente e a criação de um design sustentável.

Para a criação de um design sustentável esses princípios podem ser pensados da seguinte maneira:

- Repensar o material a ser especificado, evitando a compra de novos produtos. Quando for necessário adquirir novos materiais, se atentar ao descarte das embalagens e não jogar no lixo os materiais restantes que podem ser utilizados em outros produtos. Neste trabalho as embalagens dos produtos utilizados para acabamento foram encaminhadas para centros especifico de reciclagem.

- Reduzir a produção de novos objetos, a partir da especificação de materiais com maior durabilidade. $O$ uso de carreteis de fiação como mesas, caixas de para-brisas como estrutura de sofás, utilização de pneus como pufes e tecidos obsoletos para acabamento 
foram caminhos para a redução de novos produtos neste trabalho.

- Recusar materiais com embalagens não recicláveis. Atentando - se as empresas que tenham compromisso com o meio ambiente.

- Reutilizar materiais e objetos que foram fabricados para outras finalidades, mas que já não podem mais exercer sua real função, evitando extração de matérias-primas da natureza. Neste quesito o presente trabalho uso de pallets, caixas de para-brisas, pneu, sementes improprias para consumo, molas de suspensão de automóvel.

- Reciclar qualquer produto é reduzir automaticamente o consumo de água, energia e matéria-prima utilizada na linha de produção, além de gerar trabalho e renda. Evitou-se o desmonte total dos materiais escolhidos, reduzindo a quantidade de processos de montagem e aplicação de acabamento para o desenvolvimento dos artefatos e mobiliários.

Neste projeto todos os princípios foram levados em consideração e o mais utilizado deles foi o de reutilizar material descartado, inservível em seu uso primário, como fonte de matéria prima para desenvolvimento de mobiliário e objetos decorativos. A reutilização permite usar menos material bruto, evitando o descarte em aterros e poupando o uso de energia e água (MOXON, 2012).

\section{PROCEDIMENTO METODOLÓGICO}

Inicialmente foi desenvolvido o projeto de interiores através de estudos de layout, dos ambientes Estande Emater e Platô de descanso, e dos ambientes sala de leitura e praça interna do CEI Governador José Richa ambos localizados na Londrina-PR.

Durante a concepção do projeto técnico foi aplicado o conhecimento ergonômico para a organização do espaço e dando início aos estudos para concepção e aplicação de artefatos e mobiliários.

Para o desenvolvimento dos móveis e artefatos foram escolhidos os seguintes materiais: pneu, mangueira de combate ao incêndio, madeiras (Caixas de feira, pallet, caixa de para-brisa automotivo e restos de Medium Density Fiberboard, conhecido como MDF, de marcenarias), sementes impróprias para consumo, tecidos (cortina e jeans) e espuma de silicone.

A partir de informações coletadas em contato com empresas locais da cidade de Londrina, obteve-se informações a respeito do procedimento adotado para descarte de cada material. A seguir serão especificados a composição e formas de descarte dos materiais utilizados no trabalho.

\subsection{Composição dos materiais e formas de descarte} Com as informações obtidas em contato de empresas locais, levantou-se informações com entidades tais como a Secretarias do Meio Ambiente e Universidade Estadual de Londrina, da cidade de Londrina, em consulta a respeito de legislação e formas de descarte de resíduos na cidade.

\subsubsection{Pneu}

De acordo com Sindicato Nacional da Indústria de Pneumáticos, Câmaras de Ar e Camelback - SINPEC, a composição do pneu consiste "No pneu de passeio, a borracha predomina, sendo $27 \%$ sintética e $14 \%$ natural. O negro de fumo constitui $28 \%$ da composição. Os derivados de petróleo e produtos químicos respondem por $17 \%$, o material metálico (ou aço) por $10 \%$ e o têxtil por $4 \% "$.

$\mathrm{Na}$ região de Londrina, Paraná as empresas que comercializam pneus devem estar cadastradas no sistema da Secretaria do Meio Ambiente, com o objetivo de registrar a quantidade de pneus descartados pelas empresas que comercializam o produto. A empresa que recolhe os pneus inservíveis é a mesma que leva esse material para Curitiba para transformá-lo em pó. Esse pó é comercializado para outras empresas que desenvolvem produtos a partir desse material, como tatame, asfalto (exemplo do trecho Curitiba a Apucarana no estado do Paraná), tapete automotivo, entre outros produtos.

\subsubsection{Mangueira de combate ao incêndio}

A Associação Brasileira de Normas Técnicas - ABNT NBR 1186 define a composição das mangueiras de incêndio no item 4. Requisitos, o reforço têxtil deve ser fabricado com fios sintéticos, na qual o urdume deve ser entrelaçado com trama de fios; o tubo interno deve ser de material flexível, como borracha ou plástico.

Em relação as mangueiras de incêndio as empresas locais que disponibilizam o produto, localizadas em Londrina e região, armazenam durante $o$ ano as mangueiras substituídas, e no final do ano são descartados na empresa Kurica, (empresa que oferece serviços para coleta, tratamento e destinação final aos diferentes tipos de resíduo, tais como orgânicos, recicláveis, rejeitos, industriais, saúde e resíduos da construção civil), que separa o material de composição reaproveitável do material classificado como rejeito.

A mangueira de incêndio é composta por materiais que demandam grande mão de obra para separa-los, uma parte após a separação é classificada como rejeito, sendo descartado diretamente nos aterros sanitários pela empresa que recolhe este produto. 


\subsubsection{Madeira}

De acordo com as informações obtidas em contato com as empresas alimentícias, de transportes, e de comercialização de para-brisas, que utilizam as caixas de madeira e pallets para o transporte e armazenamento de produtos, todas as caixas em bom estado são recolhidas pela empresa para reutilizar novamente. Caso o usuário primário não aprove as condições do material este é descartado.

As sobras de madeira utilizada em marcenarias são armazenadas em barris que são recolhidas por uma empresa. Todo material recolhido é inserido em maquinas trituradoras, após a trituração este é prensado em formato de cilindros, onde são comercializados como fonte de energia para indústrias que utilizam a queima de madeira como fonte de combustível.

\subsubsection{Sementes impróprias para o consumo}

De acordo com as informações disponibilizada em contato com uma empresa cooperativa agroindustrial de Londrina, há duas formas de descarte das sementes classificadas como impróprias para consumo. Uma é enviar esse material para uma empresa de incineração localizadas em Curitiba ou Rio de Janeiro, e a outra é a compostagem desse material com outros orgânicos para gerar adubos.

\subsubsection{Tecidos, espumas e jeans}

Os tecidos utilizados nos acabamentos de alguns mobiliários destinados ao CEI foram doados pela proprietária de uma empresa local desativada. Esse material teria como destino o lixo.

No processo de confecção de produtos de vestuário são produzidos uma quantidade alta de resíduos, principalmente no processo de corte dos tecidos, onde são geradas toneladas de retalhos e muitas vezes são descartados de modo irregular em aterros sanitários, e contribuindo para o acumulo de resíduos, (MENEGUCCI, 2015).

Em uma pesquisa realizada pelo Serviço Brasileiro de Apoio às Micro e Pequenas Empresas (SEBRAE), a média de produção de resíduos têxteis é de 170 mil toneladas por ano.

Em Londrina a Universidade Estadual de Londrina, criou um programa de gestão de Resíduos interno, para recolher diversos materiais provindos da universidade, do Hospital Universitário e do alojamento estudantil. Um dos materiais recolhidos são colchões/espumas diversas e tecidos, porém este material é classificado como rejeito. O material recolhido tem como destino aterros sanitários especiais, de acordo com informações obtidas em contato com o departamento do programa.
Durante o contato com a universidade foi relatado que na região de Londrina, ainda não há empresas que recolhem os restos de material têxtil para reutilização, porém na cidade de Cianorte - PR, polo da indústria têxtil, existe tecnologia para reutilização desses resíduos. Segundo Marteli (2011) os resíduos gerados pelas empresas do ramo têxtil são encaminhados para uma empresa terceirizada objetivando a reciclagem e uso na produção de linhas e barbantes.

\subsection{Mobiliários produzidos e suas etapas de produção}

Todos os itens produzidos passaram pelas etapas descritas a seguir: concepção ( busca de material em fase de descarte, processo criativo sobre as possibilidades de concepção, estudo de desenvolvimento dos artefatos e dos mobiliário), estudo ergonômico (pesquisas para dimensionar os mobiliários a partir de normas e informações sobre ergonomia), estudo de viabilidade de utilização do material (desenvolvimento de modelo em tamanho real para demonstração e manuseio - mockup), separação e ou recorte das peças, montagem e acabamento.

A seguir serão descritos os itens produzidos e os materiais utilizados para o Estande Emater e Platô de descanso:

- Mesa (carretel de fiação). Processo: nivelamento através da lixa, e acabamento com verniz.

- Mesa de centro (pallets e molas de suspensão de automóvel). Processo: fase de desmonte, encaixe, lixamento, fixação da mola (lixada com posterior acabamento em cor), acabamento em verniz.

- Mesas de centro e de canto (caixas de feira, tecido chita). Processo: nivelamento através da lixa, aplicação de tecido e acabamento com verniz.

- Sofás (caixas de para-brisas e pallets) Processo: Recorte das caixas e da madeira para a estrutura e para o assento, lixamento e acabamento em verniz.

- Painéis decorativos. Processo: Base de madeirite, fixação de grãos impróprios para consumo, acabamento em tecido e verniz.

- Pufes (sacos de café, espuma para enchimento e pallets). Processo: nivelamento por meio de lixa, enchimento do saco de café com espuma e costura.

- Aparador (caixa de para-brisas e pallets). Processo: recorte de madeira para a superfície, fixação das madeiras recortadas na caixa para o tampo, lixamento e acabamento em verniz.

- Pufes (pneu e mangueira de incêndio). Procedimentos letapas: Serão detalhadas a seguir as etapas de produção do pufe de pneu, que são a separação do material 
e recorte das peças, preparação dos materiais, a montagem e o acabamento.

No CEl foram desenvolvidos os mobiliários abaixo:

- Sofá (pallet). Processo: Lixa, fixação e acabamento em tinta à base de água.

- Palco (pallet e tecido). Processo: Recorte, lixa, acabamento em tinta à base de água e cortina de tecido voal.

- Nichos (caixa de feira). Processo: lixa e acabamento em tinta à base de água.

- Pufe (barrica de massa corrida). Processo: Limpeza e aplicação de tecidos doados, acento preenchido com espuma de silicone.

- Estante para tv (pallet). Processo: Lixa e acabamento em tinta à base de água.

- Painel de MDF (sobras de MDF). Processo: Lixa e acabamento em tinta à base de água. E por fim a montagem de cada peça para o painel.

3.2.1 Processo de produção de móveis desenvolvidos para o estande emater e platô de descanso.

Para os ambientes Estande Emater e Platô de descanso foram desenvolvidos vários puffes feitos de pneu e mangueira de combate a incêndio. As etapas de desenvolvimento dos pufes foram as seguintes: Separação e ou recorte, preparação dos materiais, montagem e acabamento.

$\mathrm{Na}$ fase de separação e ou recorte das peças (figura 1), os pneus foram escolhidos de acordo com a largura compatível com o par e as mangueiras e parafusos necessários foram separadas.

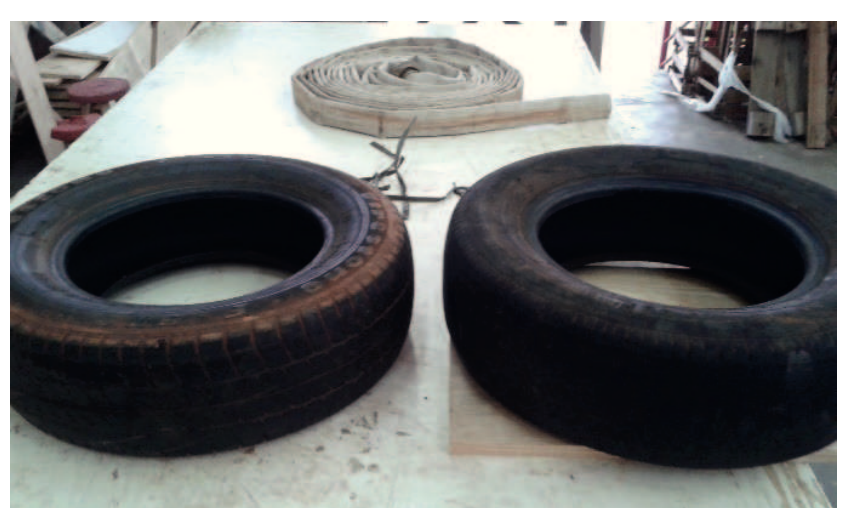

Figura 1: Material separado.

Fonte: Elaborado pelo autor

$\mathrm{Na}$ etapa de preparação dos materiais, os pneus foram limpos e as mangueiras lavadas e cortadas no tamanho pré-definido.

A montagem se deu na seguinte ordem: Primeiro um dos pneus foi furado com serra copo no fundo para não acumular água durante o uso e separado. Uma base interna de madeira foi medida e cortada para dar apoio ao acento (Figura 2). A base de madeira foi parafusada no segundo pneu.

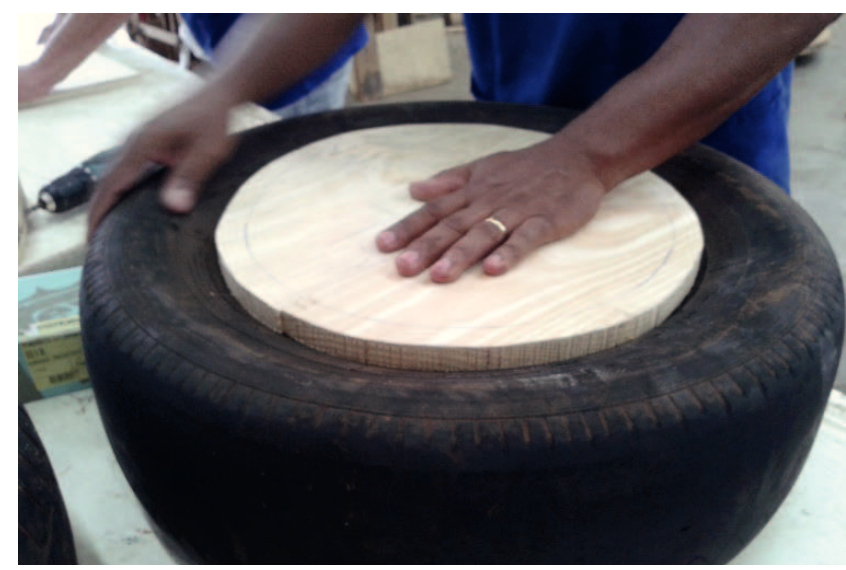

Figura 2: Teste de tamanho após corte da base Fonte: Elaborado pelo autor

Para dar acabamento, depois da base fixada as tiras de mangueira foram parafusadas uma a uma, fazendo uma trama no assento (figura 3 e 4).

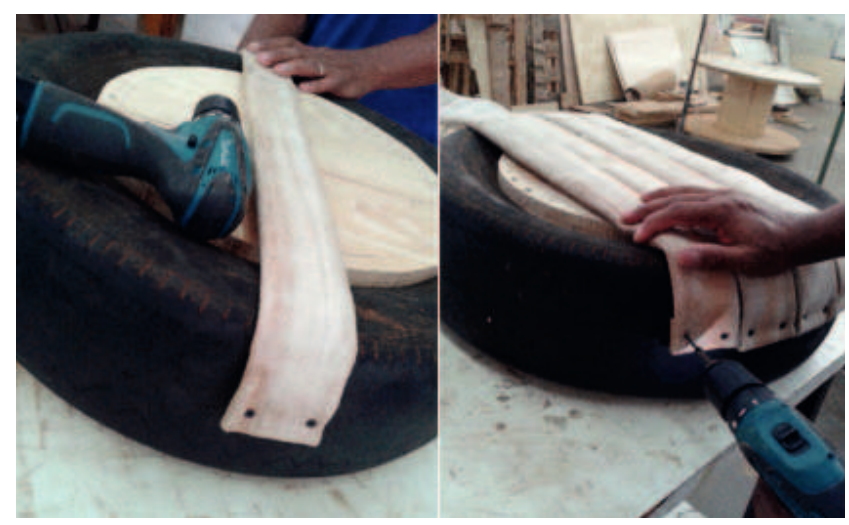

Figura 3: Fixação das mangueiras.

Fonte: Elaborado pelo autor.

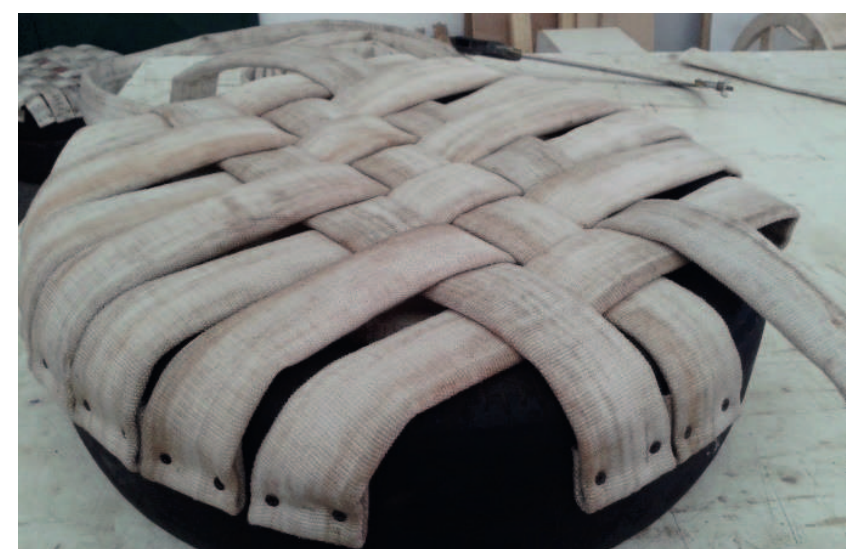

Figura 4: Trama feita com mangueiras para assento. Fonte: Elaborado pelo autor. 
Por fim, o pneu com furos na base foi parafusado, junto ao superior, dando a altura necessária para uma pessoa se sentar finalizando o móvel (figura 5).

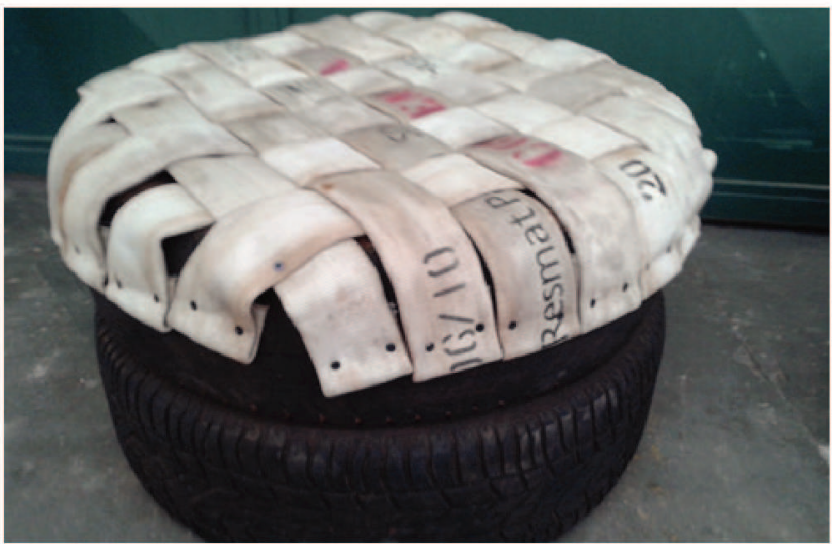

Figura 5: Produto final.

Fonte: Elaborado pelo autor.

O sofá de caixa de para-brisa passou pela fase de desmonte e fixação para o acento e encosto.

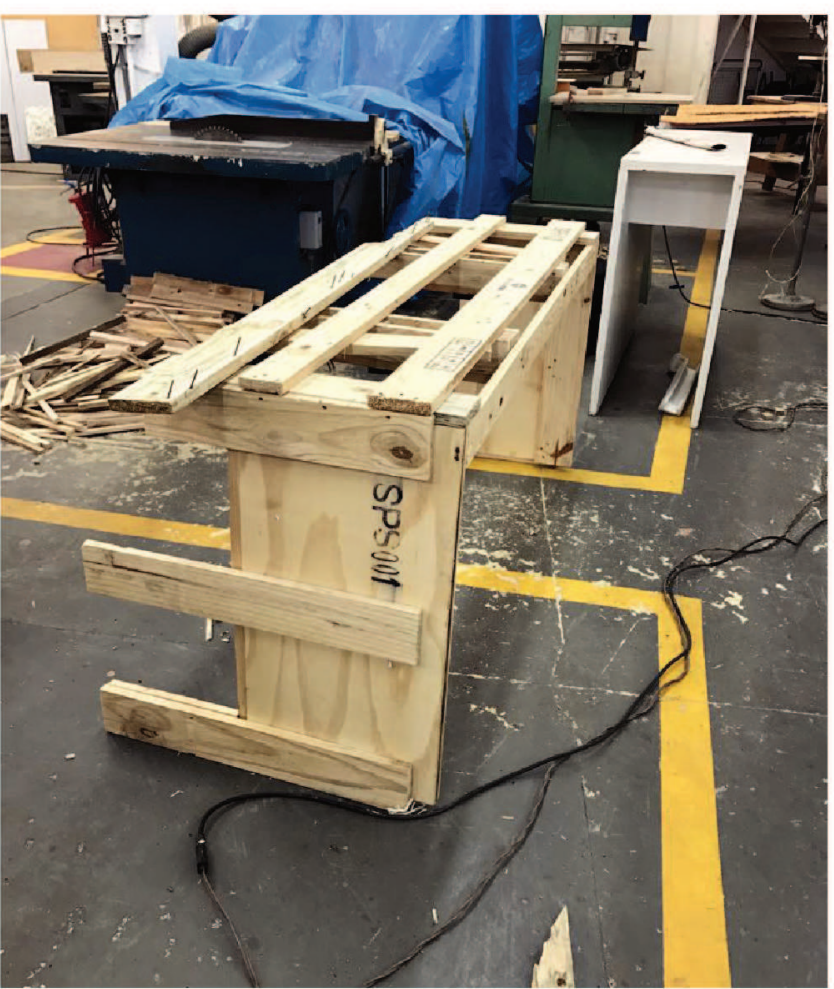

Figura 6: Preparaçăo e recorte do material. Fonte: Elaborado pelo autor.

Após a etapa de separação e ou recorte, o material passou pelas fases de nivelamento e acabamento. $\mathrm{O}$ mobiliário foi lixado para retirada de imperfeiçôes na madeira e depois recebeu duas camadas de verniz para o acabamento (Figura 7).

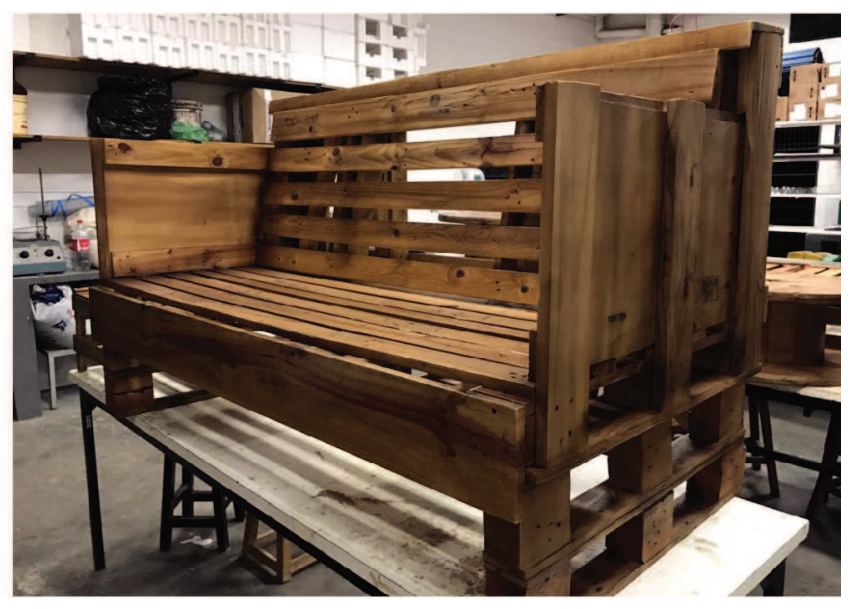

Figura 7: Produto final.

Fonte: Elaborado pelo autor.

\subsubsection{Etapas de produção dos artefatos para} - CEI Governador José Richa.

Para o Centro de Educação Infantil Governador José Richa foi confeccionado um tapete cujas matérias primas foram mangueiras de combate a incêndio condenadas que iriam para descarte. A primeira etapa foi a de separação e/ou recorte onde as mangueiras foram cortadas em tamanho pré-definido. Em seguida passaram pela etapa de limpeza e secagem, depois passaram pela fase de montagem onde as tiras foram entrelaçadas e por fim na fase de acabamento foram fixadas suas pontas, dando o formato de tapete (Figura 8 e Figura 9).

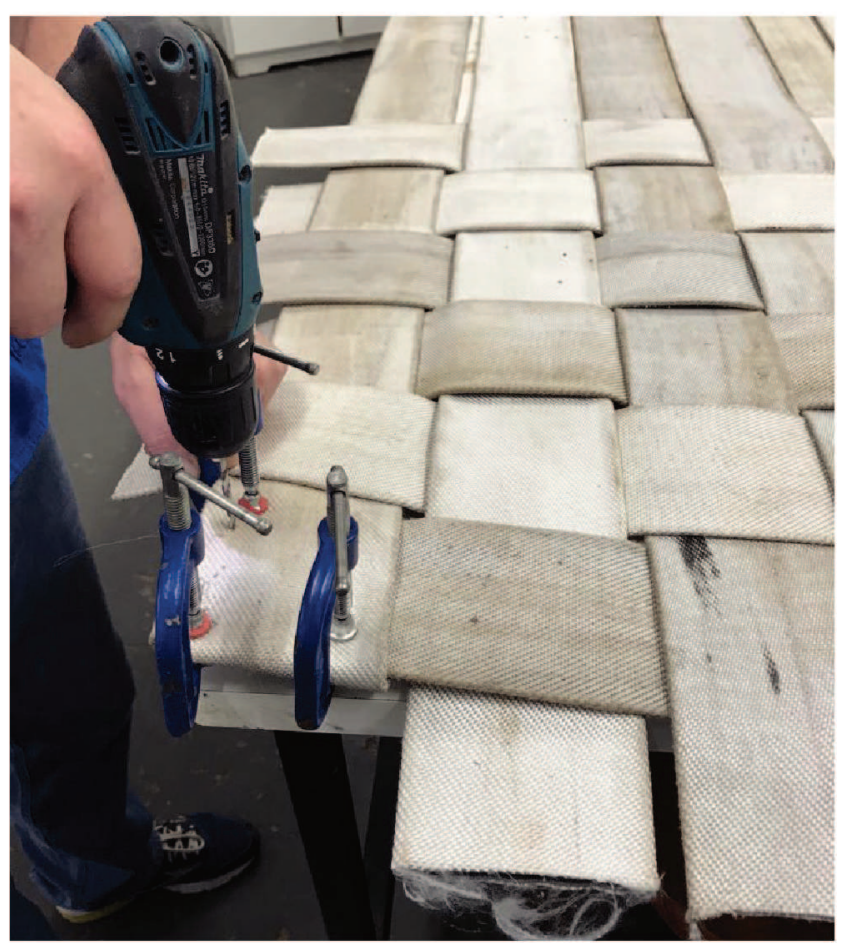

Figura 8: Confecção do tapete de mangueira de combate ao incêndio. Fonte: Elaborado pelo autor. 


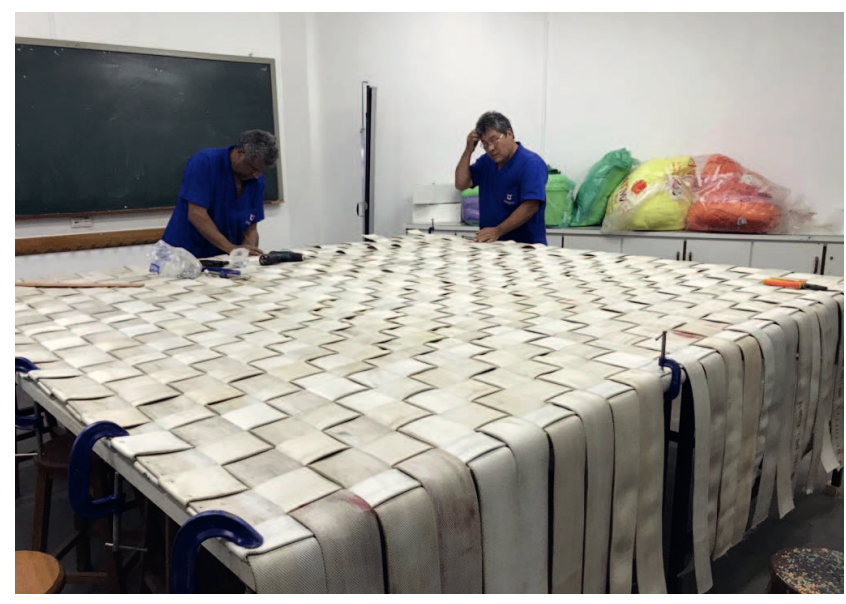

Figura 9: Tapete de mangueira de combate ao incêndio.

Fonte: Elaborado pelo autor

O sofá de pallet desenvolvido para o CEl, passou pela fase de preparação, recorte e lixamento para adequar as medidas de forma ergonômica para o uso das crianças no centro de educação (Figura 10).

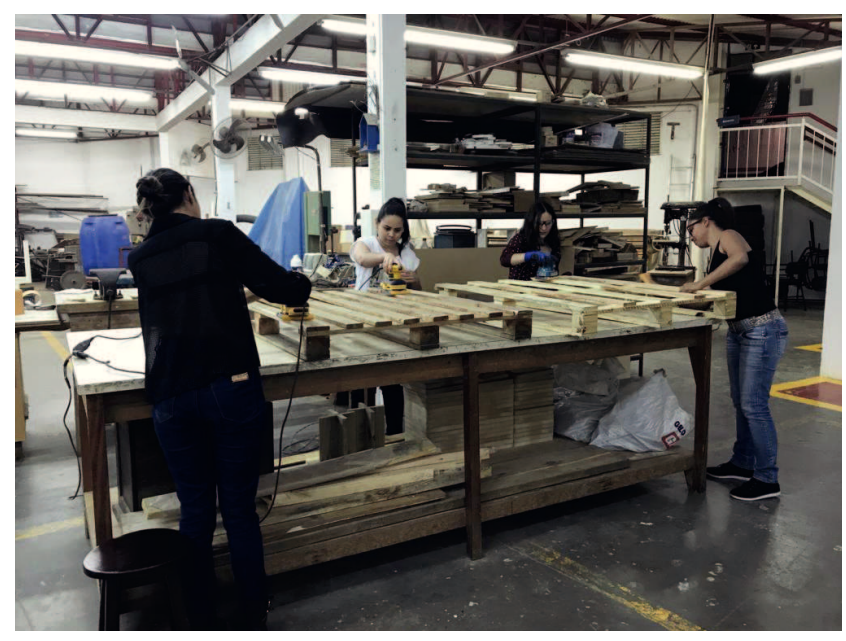

Figura 10: Fase de preparação, recorte e lixamento.

Fonte: Elaborado pelo autor

Em seguida cada peça de pallet passou pela etapa de fixação e montagem do mobiliário, dando formato ao sofá (Figura 11).

E em seguida a peça recebeu a aplicação de tinta à base de água (Figura 12 e Figura 13) e foi estofada com material já existente no centro de educação infantil. Os colchonetes usados foram cortados no tamanho correto e encapados com o tecido jeans.

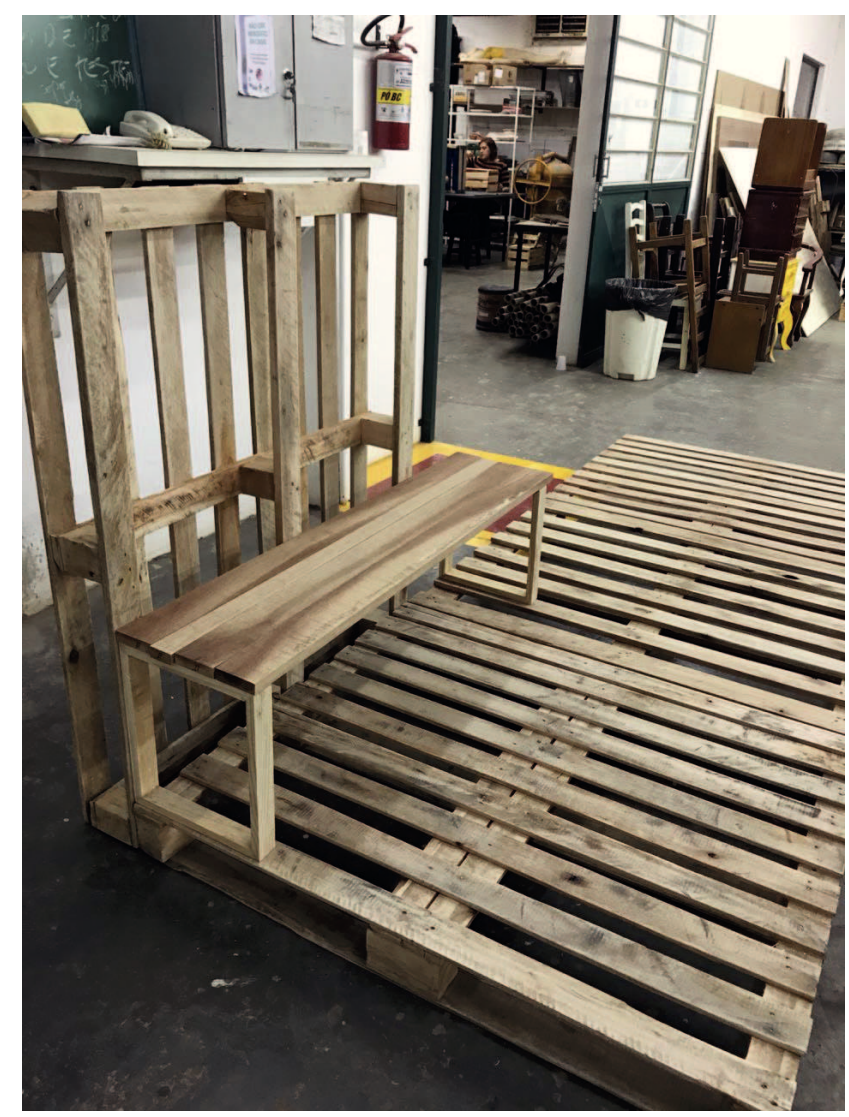

Figura 11: Montagem do mobiliário

Fonte: Elaborado pelo autor.

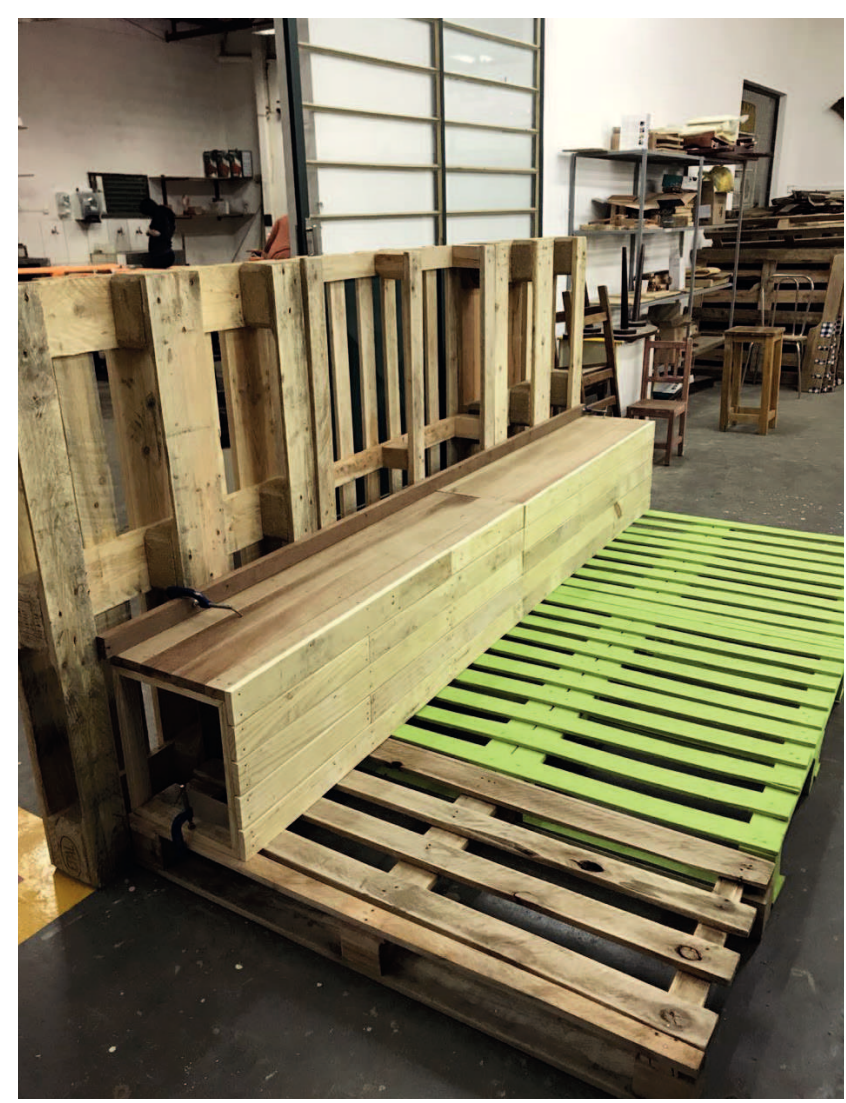

Figura 12: Aplicação da tinta à base de água. Fonte: Elaborado pelo autor. 


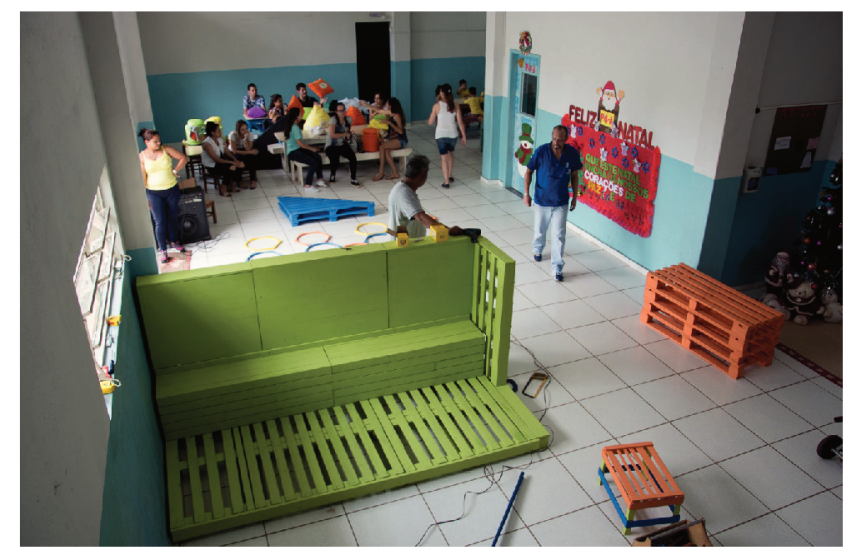

Figura 13: Produto final.

Fonte: Elaborado pelo autor.

\section{MOBILIÁRIOS E AMBIENTES DESENVOLVIDOS}

$O$ resultado obtido pelo trabalho foi a composição do estande da EMATER (figura 14), onde foram aplicados os painéis decorativos (A); a mesa de carretel (B), os pufes de saco de café $(C)$, o aparador (D), pufe de pneu (E), a mesa de centro e canto de caixas de feira (F).

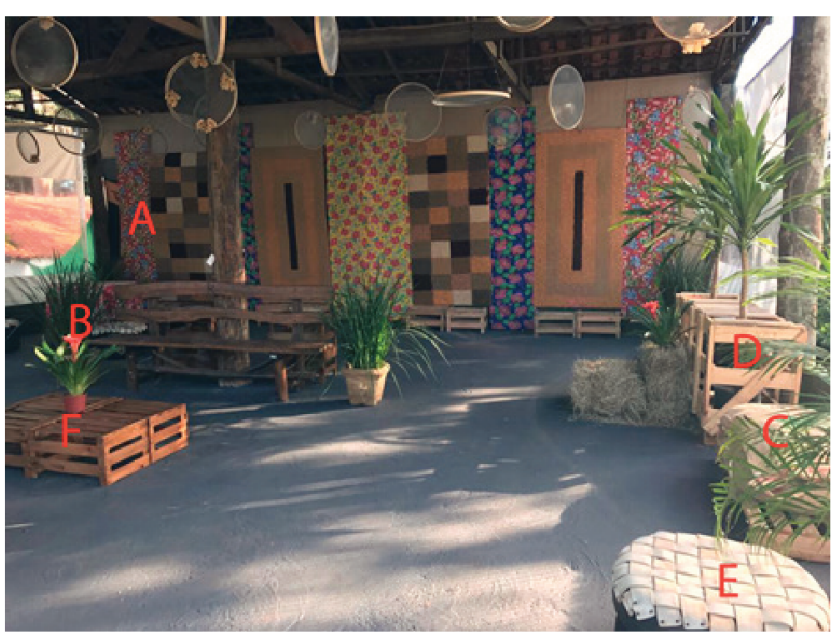

Figura 14: Estande EMATER

Fonte: Elaborado pelo autor.

Os sofás F1 e F2 (G), confeccionados com caixa de para-brisas e pallets, foram locados no segundo ambiente projetado, os platôs 1,2 e 3 (Figuras 15,16 e 17). Neles também foram inseridas mesas de carretel sendo uma com base de mola de amortecedor (B), as mesas de centro $M$ (H) e M2 (I).

Ambos ambientes também contaram com os pufes de pneu, em dois tamanhos, os pequenos e os grandes, confeccionados com pneus de carros e caminhões respectivamente, com acabamento confeccionado com mangueira de combate ao incêndio entrelaçados.

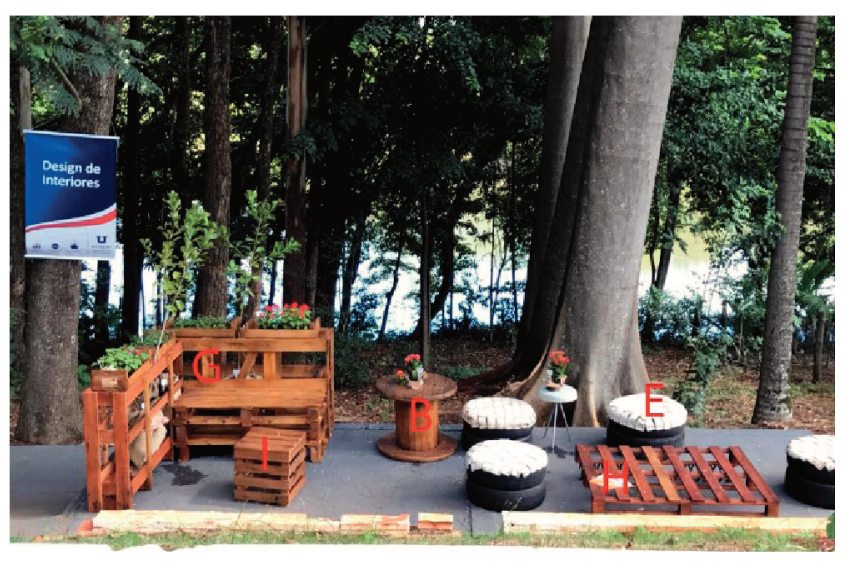

Figura 15: Platô de descanso 1

Fonte: Elaborado pelo autor.

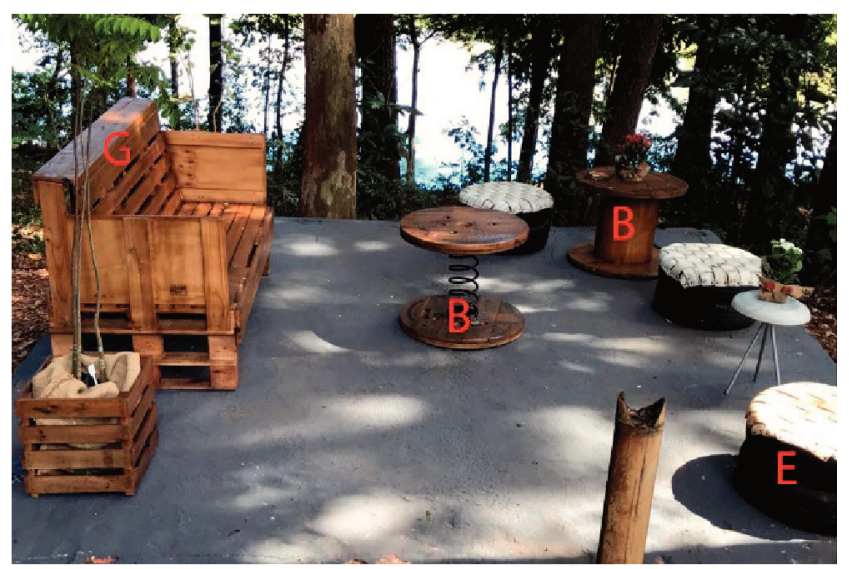

Figura 16: Platô de descanso 2.

Fonte: Elaborado pelo autor.

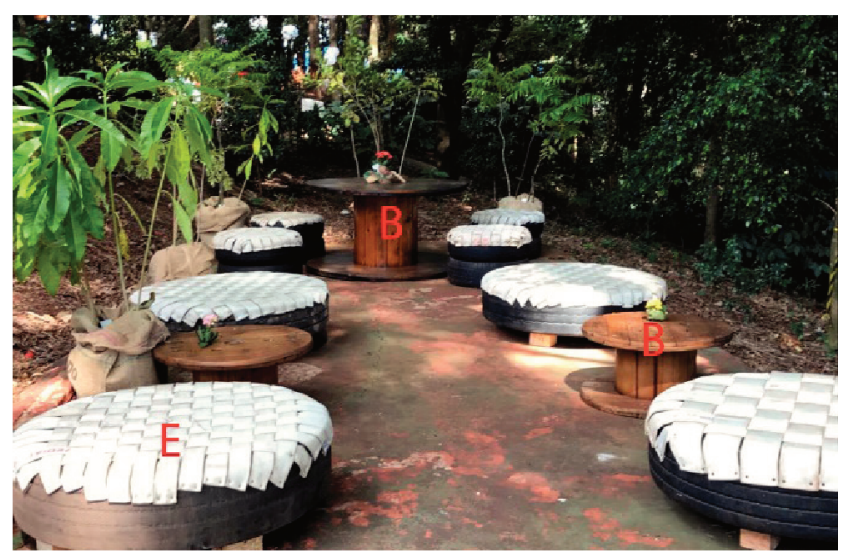

Figura 17: Platô de descanso 3.

Fonte: Elaborado pelo autor.

No centro de educação infantil Governador Jose Richa (Figuras 18 e 19) foram entregues o sofá de pallet com estofado de colchonete revestido com jeans $(\mathrm{J})$, nichos de caixa de feira $(L)$, pufes de barrica de massa corrida $(K)$, palco/cantinho de leitura de pallet com cortina de voal $(\mathrm{M})$, tapete de mangueira de combate ao incêndio $(\mathrm{N})$, a estante para tv de pallet $(\mathrm{O})$, painel de MDF (P). 


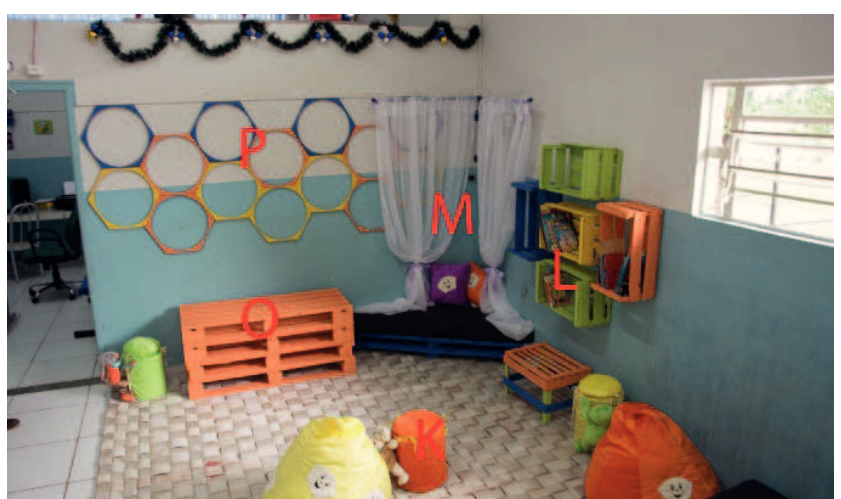

Figura 18: Sala de Leitura.

Fonte: Elaborado pelo autor

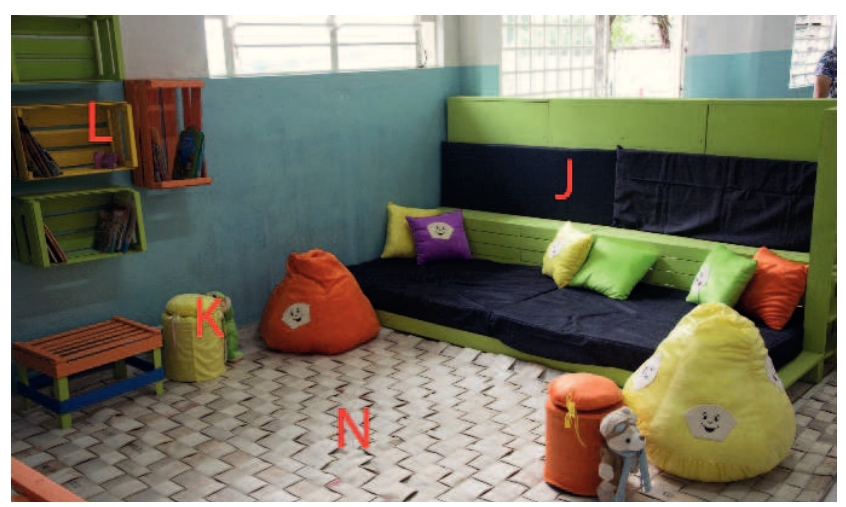

Figura 19: Sala de Leitura.

Fonte: Elaborado pelo autor

E a praça interna (Figura 20) recebeu os bancos de pallet (Q).

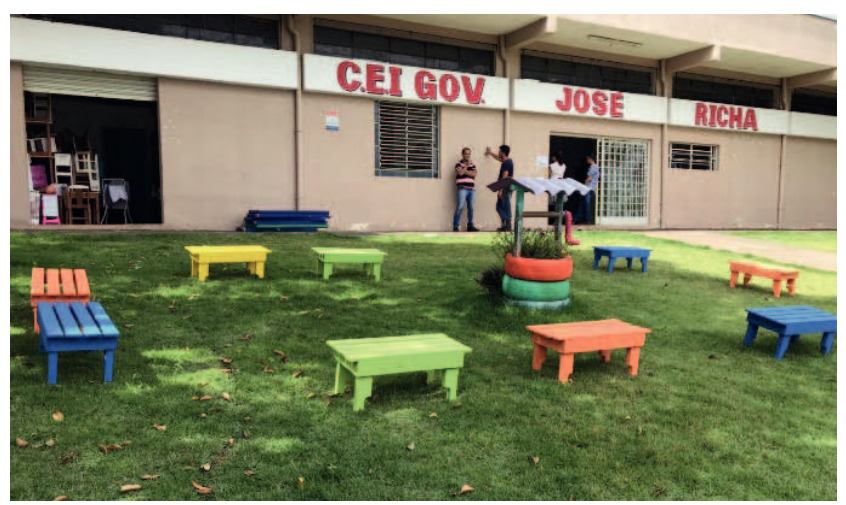

Figura 20: Sala de Leitura.

Fonte: Elaborado pelo autor

A partir da reutilização dos materiais descritos neste trabalho, foi possível desenvolver móveis e objetos decorativos com menor uso de material bruto virgem e consequentemente sem gerar resíduos. $O$ reuso previne que materiais existentes sejam descartados poupando energia e água necessárias para produzir material de substituição (MOXON, 2012).

\section{CONSIDERAÇÕES FINAIS}

O design sustentável pode ser um dos caminhos para a conscientização da população. O consumo consciente é imprescindível para que haja redução dos danos causados no meio ambiente e considerar que a natureza não é uma fonte de recursos inesgotável, segundo Coutinho (2013) e Ross (2012).

Com o desenvolvimento de móveis e artefatos, provindos de material que seriam descartados por não serem mais úteis em sua função original, podemos afirmar que a concepção e execução de móveis e objetos decorativos é possível e viável. Para Araújo (2015) os produtos do design influenciam a experiência e percepção do mundo que nos cerca.

Conclui se que é possível construir ambientes evitando o consumo de material bruto virgem, e a geração de resíduos. Enfatizando a produção do setor construtivo através do reuso de materiais, agregando valor aos produtos, ao mesmo tempo em que os diferencia frente à concorrência de mercado e proporciona desenvolvimento na regional de Londrina e região.

Este projeto leva a refletir os meios de reutilização e a aplicabilidade na atividade projetual do design, além de agregar valor e incentivar a utilização dos produtos provindos de material de descarte. $O$ trabalho realizado no projeto de extensão trouxe a comunidade conhecimento para uma cultura colaborativa que envolve menos impactos no meio ambiente, bem como incentivar o reaproveitamento e beneficiamento de materiais descartados. Estimulando a mudança de consciência da comunidade envolvida no projeto, e levar a prática de transformação de resíduos em matéria prima agregando valor ambiental, social e econômico aos produtos desenvolvidos.

Os ambientes desenvolvidos aproximaram a comunidade e os discentes da percepção sobre a sustentabilidade aplicada ao reuso de materiais em fase de descarte.

Desta forma disseminou o princípio da sustentabilidade na população que frequentou os ambientes Estande Emater e Platô de descanso durante o evento Expo Londrina 2017, bem como nos ambientes desenvolvidos no Centro de Educação Infantil Governador José Richa, ao final do ano letivo de 2017.

\section{AGRADECIMENTOS}

EXPO LONDRINA (VIA RURAL) - A parceria foi entre UNOPAR e EMATER/IAP, onde em reunião com os responsáveis pelos espaços, foi acordado a necessidades de lugares de descanso para os visitantes, realização de projeto de interiores e execução do estante EMATER Atende e da Trilha da biodiversidade. 
SALA DE LEITURA E PRAÇA INTERNA CEI - O projeto de extensão teve também vínculo com o CEI Governador José Richa, situado na Rua: Garça-real, 98 - Cj. Violim Londrina-PR, para o desenvolvimento de projeto de interiores e mobiliários que atendam suas necessidades de ambientação, acomodação e funcionamento de atividades. CEI GOVERNADOR JOSÉ RICHA - 195 crianças atendidas diariamente.

\section{REFERÊNCIAS}

AEP Associação Empresarial de Portugal. Manual Prático de Ecodesign. Dez. 2013. ISSN 978-972-8702-83-0

ARAUJO, Rosângela; FERNANDES, Valdir; RAUEN, William. Indicadores de sustentabilidade no contexto do design de produtos. Rev. Portuguesa e Brasileira de Gestão, Lisboa, v. 14, n. 2, p. 14-27, jun. 2015

CÔRTES, Rogério Gomes. FRANÇA, Sérgio Luiz Braga. QUELHAS, Osvaldo Luiz Gonçalves. MOREIRA, Marcos Muniz. MEIRINO, Marcelo Jasmim. Contribuições para a sustentabilidade na construção civil. Revista Eletrônica Sistemas\&Gestão v.6, n.3, 2011, pp. 384-

COUTINHO. Eloyse Cabral. Conceito sustentável na decoração de interiores. Revista Especialize On-line IPOG - Goiânia - 5a Edição nº 005 Vol.01/2013 - juIho/2013. ISSN 2179-5568

5 ELEMENTOS Instituto de educação e pesquisa ambiental. Consumo sustentável e manual de atividades. Coleção Consumo Sustentável e Ação, 2009. São Paulo: Imprensa Oficial do Estado de São Paulo. ISBN 978-85-7060-705-8 (Imprensa Oficial). ISBN 978-857060-711-9 (Obra Completa) (Imprensa Oficial).

JUNIOR, Adelson Moura da Silva; LIMA, Sandovânio Ferreira de. Ecodesign e análise do ciclo de vida: Futuro Sustentável. Ciências exatas e tecnológicas | Maceió | v. 2 | n.3 | p. 47-62 | Maio 2015. ISSN IMPRESSO 1980-1777. ISSN ELETRÔNICO 2357-9919.

JUNIOR, Joel Vieira Baptista. ROMANEL, Celso. Sustentabilidade na indústria da construção: uma logística para reciclagem dos resíduos de pequenas obras. Urbe. Revista Brasileira de Gestão Urbana. v. 5, n. 2, p. 27-37, jul/dez. 2013.

GIRARDI, Giovana. Brasil produz lixo como primeiro mundo, mas faz descarte como nações pobres. Disponível em: http://sustentabilidade.estadao.com. br/blogs/ambiente-se/brasil-produz-lixo-como-primeiro-mundo-mas-faz-descarte-como-nacoes-pobres/ Acesso em 27 fev. 2018.

LIMA, Ana Karmen Fontenele Guimaraes. Consumo e sustentabilidade: em busca de novos paradigmas numa sociedade pós-industrial. XIX Encontro Nacional do CONPEDI. Fortaleza - CE 12 de jun. de 2010.

MARTELI, Andrei Jose Santos. Análise do gerenciamento de resíduos de tecidos sintéticos nas empresas de confecções do Município de Cianorte. Dissertação (mestrado profissional) - Universidade Federal do Paraná, SENAI - PR, Universität Sttutgart, Setor de Tecnologia, Programa de Pós-Graduação em Meio Ambiente Urbano e Industrial. Curitiba, 2011.

MENEGUCCI, Franciele; MARTELI, Letícia; CAMARGO, Maristela; VITO, Meriele. Resíduos têxteis: Análise sobre descarte e reaproveitamento nas indústrias de confecção. Congresso Nacional de Excelência em Gestão. Rio de Janeiro - RJ. 13 e 14 de agosto de 2015. ISSN 1984-9354.

MOXON, Siân. Sustentabilidade no Design de Interiores.São Paulo:G.Gilli, 2012.ISBN: 9788425224836

NBR 11861. Mangueira de incêndio - Requisitos e métodos de ensaio. ABNT -Associação Brasileira de Normas Técnicas. Out. 1988.

PANERO, Julius. MARTIN, Zelnik. Dimensionamento humano para espaços interiores. São Paulo: G. Gilli, 2014. $1^{\text {a }}$ edição. 10a publicação. ISBN: 9788425218354

ROSS, Alana. BECKER, Elsbeth Leia Spode. EDUCAÇÃO AMBIENTAL E SUSTENTABILIDADE. Revista Eletrônica em Gestão, Educação e Tecnologia Ambiental. REGET/UFSM. v(5), n5, p. 857 - 866, 2012. e-ISSN: 2236-1170

RETALHOS DE TECIDOS: NO LUGAR DO DESPERDÍCIO, NEGÓCIOS SUSTENTÁVEIS. SEBRAE. Disponível em: http://www.sebraemercados.com.br/retalhos-de-tecidos-no-lugar-do-desperdicio-negocios-sustentaveis/ Acesso em 06 de setembro de 2018. 
REZENDE, G.B.M; BRITO, A.L.C; FREITAS, L.S. A pratica do ecodesign na construção civil e a busca pelo direito fundamental ao meio ambiente ecologicamente equilibrado. HOLOS, Ano 33, Vol 04. ISSN 1807-1600. DOI: 10.15628/holos.2017.3961

SINPEC - Sindicato Nacional da Indústria de Pneumáticos, Câmaras de Ar e Camelback. Matériaprimas. Disponível em: http://www.fiesp.com.br/ sinpec/sobre-o-sinpec/historia-do-pneu/fabricacao/ Acesso em: 22 de nov. 2017.

PROGRAMA DE GESTÃO AMBIENTAL DA UEL. Disponível em: http://www.uel.br/programas/reciclauel/ Acesso em 06 de setembro de 2018.

\section{AUTORES}

ORCID: https://orcid.org/0000-0001-8178-3438

ANA LÚCIA KEIKO NISHIDA Esp. | Universidade Norte do Paraná | Design de Interiores | Palhoça, SC. Brasil | Correspondência para: R. Pref. Reinoldo Alves, 41 - Passa Vinte, Palhoça - SC, 88132-000 | E-maill: ananishida@live.com

ORCID: https://orcid.org/0000-0003-4595-0758

DAMARES LUIZA SILVEIRA DE CARVALHO, M.Sc | Universidade Norte do Paraná | Design de Interiores | Palhoça, SC. Brasil | Correspondência para: R. Pref. Reinoldo Alves, 41 - Passa Vinte, Palhoça - SC, 88132-000 | E-maill: damarescarvalho@gmail.com

\section{COMO CITAR ESTE ARTIGO}

NISHIDA, Ana Lúcia Keiko; CARVALHO, Damares Luiza Silveira de. Design de Interiores como Ferramenta para a Sustentabilidade. MIX Sustentável, [S.I.], v. 4, n. 3, p. 77-87, out-mar. 2018. ISSN 24473073. Disponível em:<http://www.nexos.ufsc.br/index.php/mixsustentavel>. Acesso em: dia mês. ano. doi:https://doi. org/10.29183/2447-3073.MIX2018.v4.n3.77-87.

DATA DE ENVI0: 11/09/2018

DATA DE ACEITE: $25 / 09 / 2018$ 